This is a pre-copyedited, author-produced PDF of an article accepted for publication in Journal of Business Research following peer review. The version of record [Journal of Business Research (May 2016) 69 (5): 1534-1538, first published online 28 October 2015] is available online at doi: 10.1016/j.jbusres.2015.10.012

(C) 2016. This manuscript version is made available under the CC-BY-NC-ND 4.0 license http://creativecommons.org/licenses/by-nc-nd/4.0/ 


\title{
New structured knowledge network for strategic decision making in IT innovative and implementable projects
}

\author{
Ali Alkhuraiji, University of Plymouth \\ Shaofeng Liu, University of Plymouth \\ Festus Oluseyi Oderanti, University of Plymouth \\ Phil Megicks, University of Plymouth
}

July 2015

The authors thank Dr Jonathan Moizer and Dr Irina Neaga from University of Plymouth for their careful reading and suggestions. Send correspondence to Ali Alkhuraiji, University of Plymouth, Plymouth, Devon, PL4 8AA, UK (email:

ali.alkhuraiji@plymouth.ac.uk); Shaofeng Liu, University of Plymouth, Plymouth, Devon, PL4 8AA, UK (email: shaofeng.liu@plymouth.ac.uk); Festus Oluseyi Oderanti, University of Plymouth, Plymouth, Devon, PL4 8AA, UK (email: Festus.Oderanti@Plymouth.ac.uk); Phil Megicks, University of Plymouth, Plymouth, Devon, PL4 8AA, UK (email: phil.megicks@plymouth.ac.uk). 


\begin{abstract}
This study investigates the development of a structured knowledge-network model in information technology (IT) innovative and implementable projects to facilitate knowledge sharing and transfer in a multi-organization context. The study employs a practice-based perspective by using an exploratory case-study approach and a combination of thematic analysis and comparative analysis to analyze the data across public organizations, private organizations, and international companies. The results identify organizational factors and their influence on knowledge channels and knowledge networks. The study contributes to organizational, administrative and knowledge management theories regarding organizational strategy, organizational culture, organizational capacity, knowledge network externalities, knowledge network intermediaries, and knowledge network infrastructures.
\end{abstract}

Keywords: Knowledge networks; knowledge channels; knowledge sharing, knowledge transfer 


\section{Introduction}

In recent years, knowledge management is experiencing a paradigm shift regarding the source of competitive advantage: From economies of scale to economies of "know-how" (Sambamurthy \& Subramani, 2005). Organizations are facing new challenges, including collaborative learning, organizational learning, knowledge sharing and transfer across strategic alliances, and operation of network structures, including intra and inter firm's strategic coupling within dynamic relationships (Andersson et al., 2007; Gupta \& Polonsky, 2014). Knowledge networks emerge to help meeting the above challenges. The meaning of networks in such context relates to connections, linkages, action, brokering, and intermediaries that require systematic action to build strategic knowledge networks for knowledge mobilization (Hislop et al., 2000; Jashapra, 2011).

A formal knowledge network usually consists of expert institutions sharing the group's common interests and concerns. This knowledge network attempts to increase the understanding of a particular knowledge topic and enhances the capacity of grasping such knowledge to deliver solutions for particular decision problems (Alkhuraiji et al., 2014). Following the SECI model (Nonaka \& Takeuchi, 1995), four types of knowledge networks exist: Knowledge networks of interaction, knowledge networks of interpretation and translation, knowledge networks of influence, and institutional knowledge networks (Gourlay, 2003). This classification is vital to connect different parties of multi-organizational corporations such as knowledge brokers, intermediaries, boundary spanners, stakeholders, vendors, resources, key product/service creators/providers, and key value-adding activities. Creating a comprehensive knowledge network between industries is a motivating force to mobilize knowledge and to deliver effective knowledge that organizations can use as a commodity. Thus, establishing a knowledge network in IT innovative projects is a key approach to capacity development that seeks not only to enhance organizational-readiness 
capacity but also to draw upon a large amount of expertise to support strategic decisions (Alkhuraiji et al., 2014). A strategic knowledge network can help to maintain the integration of knowledge into business operations. For instance, some knowledge providers may justify the reason for isolating knowledge as a commercial secret, whereas isolating knowledge from a receiver's perspective is time-consuming and increases cost. However, knowledge networks facilitate cost reduction by recruiting expertise and searching for isolated knowledge and noncodified knowledge (Villasalero, 2014).

Structured knowledge-networks can have a significant effect on knowledge sharing and transfer, hence delivering a more effective solution for a knowledge-exchange process (Liu et al., 2014; Reagans \& McEvily, 2003). Less time and effort in understanding knowledge sources equals less cost of knowledge transfer. A key point of structured networks is knowledge traceability, which can greatly facilitate knowledge integration across alliances (Etemad \& Lee, 2003). Knowledge networks usually occur in response to a unique set of circumstances but addressing the effectiveness of such networks, their structure and governance, efficiency, the availability of resources, and sustainability is vitally significant.

This study focuses on exploring new structured knowledge-network models that can support knowledge sharing and transfer in IT projects across three types of organizations: Public organizations, private organizations, and international companies. The article follows this structure: After presenting the theoretical framework for the study, section 3 offers the method; section 4 presents the findings of this study. Section 5 discusses the study's conclusions and limitations.

\section{Theoretical Framework}

Recent work in knowledge management provides four main theories regarding the conceptualization of inter-organizational issues. These theories are process theory, system theory, network theory, and actor-network theory (ANT) (Olsen et al., 2014). Process theory 
provides conceptual frameworks on knowledge creation processes that align with ANT, whereas system theory focuses on the interrelationships among divisions and units in their business environment. Network theory tends to focus on the structures and dynamics of such interrelationships (Alexander \& Silvis, 2014).

Although this research seeks to clarify how knowledge networks initiate and how they benefit organizations, the research employs the ANT to examine the network interactions between different parties in product/service value chains. ANT explains the interactions among actors within a network and how such actors unite by using non-human actors (i.e., artifacts) to increase the potential for more alliances so as to achieve common interests (Mahring et al., 2004; Nielsen 2005). ANT perceives an actor as the central point of an action irrespective of being a human or non-human. ANT views technology as an emergent concept from social interest that can have the potential to shape social interaction (Doolin \& Lowe, 2002). ANT's epistemological and ontological stance perceives the world as a network of nodes that include people, objects, concepts, and ideas. This theory focuses on network structure, how networks originate, how such networks can relate to other networks, and how actors enroll into a network (Alexander \& Silvis, 2014). Many information system (IS) studies argue that the key benefit of using ANT is facilitating the understanding of the complex socio-technical issues (Alexander \& Silvis, 2014; Olsen et al., 2014; Underwood, 2008). For example, scholars use ANT to examine the introduction into an organization technology that may affect the whole network.

ANT also defines the difference between intermediaries and mediators in terms of their outputs. The intermediaries' outputs are easy to predict on the basis of their inputs, whereas mediators' outputs are unpredictable. This differentiation is beneficial to social issues in which outcomes are most frequently unpredictable (Underwood, 2008). IS studies also use ANT to facilitate the interpretation of the political processes of IT innovation and 
implementation (Cresswell et al., 2010). However, scholars rarely use ANT to explore knowledge sharing and transfer issues, especially knowledge networking and mobilization in a multi organization context to facilitate the smooth flow, tracing, and integration of knowledge (Erden et al., 2014).

This study fills a gap in current research by using ANT to explain how to construct and structure knowledge networks, the consequences from building such networks, and the key factors influencing their construction.

\section{Method}

This study adopts an exploratory approach. A case study method is appropriate due to its inherent flexibility as well as its efficacy in addressing complex issues and embedded relationships for certain markets (Dubois \& Araujo, 2004; Woodside, 2013). The datacollection process took place over one year and a half in two stages. The setting of this research is Saudi Arabia. The sample comprised thirty-four participants from seven large organizations including leading international companies and local companies (software and hardware) and public organizations in IT project practice, plus experts from consultancy services. The study used two sampling techniques: The purposive sampling technique at the early stage to identify initial participants who were in charge of IT projects in terms of planning, evaluation, execution, implementation, and post-implementation; a snowball sampling technique in the second stage to identify further informants (Dubois \& Araujo, 2004). The main criteria for selecting the samples were: (a) Companies should have more than five years of involvement in IT projects, consultancy, business evaluation, and restructuring ; (b) companies should have ongoing interactions between the decision makers (i.e., providers and users) to investigate issues regarding their collaborative practice. The study carried out thirty-four in-depth, face-to-face, semi-structured interviews, each lasting between 45 minutes and two-and-half hours, with the pertinent recording and transcription. Participants included 
directors, chief executives, and general managers from public, private local and international organizations conducting IT projects. Table 1 provides an overview of the participants and their organizations.

Table 1 here.

This research used a combination of thematic and comparative analysis for data analysis. The authors used thematic analysis method to analyze the qualitative empirical data, including the initial code generation, identification of meaningful themes, revising such themes, and defining and naming the categories (Braun \& Clarke 2006). The data analysis through NVivo software (Bazeley \& Jackson, 2013) enabled the production of a thematic map.

The comparative analysis method is useful for cross-case analysis to examine new themes across all cases and to detect the strength of evidence from empirical data (Tharenou et al., 2007). This research used comparative analysis to confirm the empirical findings across the eight cases where there was less support from the literature. In addition, the comparative analysis enabled the identification of the point of data saturation, thus establishing that further interviews were not necessary.

\section{The research findings}

\subsection{Organizational factors}

Three organizational factors emerge from the empirical study: Organizational strategy, organizational culture, and organizational capacity.

\subsubsection{Organizational strategy}

The authors identify different practices from the three sets of samples (i.e., public organizations, private local organizations, and international organizations). These 
organizations have different roles in managing IT projects: Hardware and software vendors (e.g., international private companies); knowledge brokering and knowledge mediators (e.g., local private companies specialized in software implementation and local E-service programs); IT solution-seekers (e.g., governmental or public organizations); and full IT project management, which includes initiation, consultation, execution, implementation, evaluation, and post implementation. Figure 1 illustrates a structured knowledge-network model that includes the roles of the companies and main knowledge channels within the knowledge network. The model comprises two parts. The first part explains how governmental organizations seek IT solutions; the second part shows how international and local companies provide IT solutions to public or governmental organizations.

The model identifies the function of PYR in trying to play the role of knowledge brokering on one hand, and raising the awareness of public organizations on the other hand. The interviewees explain some communication channels issues regarding the alignment of IT projects alongside the organizational strategies. A business analysis director from IPC declares:

Some public organizations seek IT solutions whereas they cannot identify their needs, their organizational strategies are not clear, no clear vision or missions. When we propose overall organizational re-engineering they become unhappy, so we just propose an IT system that can do the work for short term. We may know that the projects will not last for that long, but we have to do the job. Interestingly we had organizations that seek IT solutions because they want to be like another organization in terms of IT use, of course in the end it is a market so we have to sell our products. Our responsibility is to raise the awareness, but sometimes we cannot make the decision for them." 
Strategic management is the predominant characteristic of the international companies and, to some extent, of private local organizations. One of the strategies is to extract cultural knowledge from private local companies and to have those local companies as partners in dealing with governmental organization's projects. A project manager from one international company comments:

Private local organizations are our strategic partners in terms of building knowledge sharing communities, enhancing our business practices in such area and engaging them in some complex projects and sharing best practice. These multicultural communities provide chances for exchanging expertise and bridging the way to the local market. For IT implementation services, we have some classification for private local companies based on their historical records in cooperating with us.

Most of the interviewees bring concerns on policy and procedural issues, particularly with the introduction of new IT systems in an organization. For example, international companies and private local companies lay the charge at governmental organization's doors in terms of lacking a clear policy and procedure. One expert claims the following:

When revising the contract of an IT projects we always bring concerns on the ambiguity of the goals and objectives. Most of organizations are not capable of conducting project request of proposals by themselves, we try to do our best to help, but we cannot get all information needed easily. No standard project methodology is followed by some of the public organizations.

The interviewees explain the importance of having clear policies, procedures, projects, objectives, and requirements, which facilitates organization's effectiveness by eliminating issues of politics such as the lack of coordination among divisions and the lack of cooperations within external industries.

Figure 1 here. 


\subsubsection{Organizational culture}

The data analysis reveals that most public organizations adopt a silo mentality where divisions, departments, or groups resist sharing knowledge with others. Most of the interviewees point out that from the outset of an IT project a corporate mentality seems to exits; however, when other departments need knowledge the silo culture seems to be dominant. A project manager in ISS who deals with large IT system integrations claims: "projects delays or failures attribute strongly to the lack of transparency especially in the planning stage. Transparency is the key to put everything on the right track and move further."

Others suggest that the lack of transparency is a result of inadequate training on community-of-practice systems or lacking reward systems — if present at all —in some organizations. These factors can damage the trust level between employees and the organization.

One knowledge management officer in a private company states that:

Public organizations are not willing to cooperate with internal management and that's why they rely on outsourcing companies to do their work; it is a matter of complex culture. For example, we were assigned to implement an IT system after it had some delay due to the lack of cooperation inside the organization with the project team. It was managed internally and had been handed to us after there were delays, we managed to get it done within the time and cost proposed. That is why I think there is always need for outsourcing.

\subsubsection{Organizational capacity}

Organizations need to identify, discuss, and resolve their organizational capacity before the adoption of an IT system. Some issues include organizational readiness in terms of 
resource availability, experts, organization IT maturity, IT structure, infrastructure, and budget. One of the key successes in IT projects is resource allocation. One consultant at an interview claims:

An adequate budget has to be allocated and the required resources such as training courses, educational programs and consultation have to be established. There is also a need that the new system introduced has to be compatible with the existing system and that current infrastructure is ready to accommodate the new system.

\subsection{Factors influencing knowledge channels in knowledge networks}

\subsubsection{Knowledge network's externalities}

(a) Internal factors: The interviewees clarify that some internal networks consist of links of communication channels that coordinate their industry knowledge regarding IT projects in terms of production, development, and innovation activities. On the one hand, these networks aim to enhance the flow of an organization's resources; on the other hand, some networks diffuse knowledge. Thus, knowledge networks can be formal and informal. For example, business reports, conferences, seminars, and structural organizational procedures are formal knowledge networks. However, common knowledge interests, shared value, and political and cultural involvement can affect an informal knowledge network. A business analyst reveals:

We hear about the term knowledge networks, but what we have are not knowledge networks, they are business networks defined by job roles. Knowledge networks are not explicitly defined in order to be efficient. The main barrier is the misconception between knowledge networks and business networks.

(b) External factors: The findings suggest that the external pressure of the IT industry on public organizations to develop their IT services shapes non-strategic knowledge networks, 
most of which would not last to the end of an IT-project implementation. A knowledge officer claimed that "some decisions are made subjectively based on a success story of an IT project somewhere else."

\subsubsection{Knowledge intermediaries}

The interviewees explain the role of knowledge brokering as connecting different parties into a common knowledge topic, raising issues, providing best practices, and becoming the master key in connecting decision makers to the sources of knowledge. However, the lack of knowledge interpretation, translation, and documentation cannot show the value of knowledge brokering activities. Project managers of private companies believe that decision makers in an organization have to understand, interpret, translate, evaluate, and implement knowledge-brokering activities.

\subsubsection{Knowledge management infrastructure}

The data analysis identifies that knowledge infrastructure, including knowledge management strategies, processes, tools (e.g. IT communication systems), and the knowledge base, could contribute to shaping a strategic knowledge channel. A project manager from an international company who specializes in IT project implementation in the public sector claims that: "Having a solid knowledge of infrastructure alongside knowledge base allows companies to have standardization in IT project advertising, marketing, innovation, implementation, and evaluation."

\section{Discussion and conclusions}

Although knowledge networks are critical solutions for knowledge sharing and transfer, the adoption of knowledge network models remains significantly low among business organizations according to the findings of this study. Understanding the issues of building a structured knowledge-network is difficult and subject to the business context. This 
research examines several issues that arise when trying to build structured knowledge networks for strategic decision-making in IT innovative and implementable projects.

Researchers commonly use actor-network theory (ANT) in practical settings due to its robustness in explaining the systematic way of considering the infrastructure surrounding technological achievements. The empirical results reveal that organizational factors and their influence on knowledge channels and knowledge networks play an important role on the implementation of structured knowledge networks. Previous studies examine organizational factors that affect knowledge sharing (Walter et al., 2007), but ignores aspects of the external and internal networks of an organization regarding the networks' capabilities to obtain and share knowledge. Thus, this study extends and contributes to knowledge by modelling structured knowledge-network interaction using a more holistic approach. This research makes a clear contribution to organizational and administrative theory in three respects: organizational strategy, organizational culture, and organizational capacity. Organizational Strategy is a core element in shaping structured knowledge networks, issues of strategic alliance, partnership, policy and procedure, as well as knowledge networks governance. Organizational culture deals with the level of transparency in organizations, which also affects structured knowledge networks. Organizational capacity provides details on an organization's IT maturity, IT structure, infrastructure and budget, thus determines the allocation of resources.

Three main factors influence knowledge channels: Knowledge network externalities, knowledge intermediaries, and knowledge management infrastructure. Internal organizational factors are those actors that coordinate the processes of development and innovation as well as the process of sharing an organization's resources. Knowledge brokering is a master key in connecting decision makers to the sources of knowledge; knowledge infrastructure contributes to shaping strategic knowledge channels. 
A key limitation of the study is that the empirical data comes from 34 interviews across eight cases of public, private, and international companies in Saudi Arabia. To be able to generalize the findings, further research should investigate the structured knowledgenetwork model this study proposes in other national and cultural settings. Additional studies may also explore the model, its components, and relationships with further case studies to establish its viability as a mean to understand structured knowledge networks and strategic decision-making. 


\section{References}

Alexander, P. M., \& E. Silvis (2014). Actor network theory in information systems research. Information Research - an International Electronic Journal, 19(2), paper 617. Available at http://InformationR.net/ir/19-2/paper617.html]

Alkhuraiji, A., Liu, S., Oderanti, F. O., Annansingh, F., \& Pan, J. (2014). Knowledge network modelling to support decision-making for strategic intervention in IT project-oriented change management. Journal of Decision Systems, 23(3), 285-302.

Andersson, U., Hohn, D. B., \& Johanson, M. (2007). Moving or doing? Knowledge flow, problem solving, and change in industrial networks. Journal of Business Research, 60(1), 32-40.

Bazeley, P. \& Jackson, K. (2013). Qualitative Data Analysis with NVivo (2 ${ }^{\text {nd }}$ edition). Sage. London, UK.

Braun, V., \& Clarke, V. (2006). Using thematic analysis in psychology. Qualitative Research in Psychology, 3(2), 77-101.

Cresswell, K. M., Worth, A., \& Sheikh, A. (2010). Actor-Network Theory and its role in understanding the implementation of information technology developments in healthcare. BMC Medical Informatics and Decision Making, 10(1), 67.

Doolin, B., \& Lowe, A. (2002). To reveal is to critique: Actor-network theory \& critical information systems research. Journal of Information Technology, 17(2), 69-78.

Dubois, A., \& Araujo, L. (2004). Research methods in industrial marketing studies. Chichester, UK: Wiley.

Erden, Z., Klang, D., Sydler, R., \& Von Krogh, G. (2014). Knowledge-flows and firm performance. Journal of Business Research, 67(1), 2777-2785. 
Etemad, H., \& Lee, Y. (2003). The knowledge network of international entrepreneurship: Theory and evidence. Small Business Economics, 20(1), 5-23.

Gourlay, S. (2003). The SECI model of knowledge creation: some empirical shortcomings. The 4th European Conference on Knowledge Management, 18-19 Sep 2003, Oxford, England.

Gupta, S., \& Polonsky, M. (2014). Inter-firm learning and knowledge-sharing in multinational networks: An outsourced organization's perspective. Journal of Business Research, 67(4), 615-622.

Hislop, D., Newell, S., Scarbrough, H. \& Swan, J. (2000). Networks, knowledge and power: Decision making, politics and the process of innovation. Technology Analysis \& Strategic Management, 12(3), 399-411.

Lee, D.-H. (2011). The effect of alliance capability on alliance performance in high-tech industry: Knowledge sharing as mediator. Journal of Business Research, 26(4), 91112.

Liu, S., Moizer, J., Megicks, P., Kasturiratne, D., \& Jayawickrama, U. (2014). A knowledge chain management framework for global supply chain integration decisions. Production Planning and Control, 25(8), 639-649.

Mahring, M., Holmstrom, J., Keil, M., \& Montealegre, R. (2004). Trojan actor-networks and swift translation: Bringing actor-network theory to IT project escalation studies. Information Technology \& People, 17(2), 210-238.

Nielsen, B. B. (2005). The role of knowledge embeddedness in the creation of synergies in strategic alliances. Journal of Business Research, 58(9), 1194-1204.

Nonaka, I., \& Takeuchi, H. (1995). The Knowledge Creating Company: How Japanese Companies Create the Dynamics of Innovation, New York: Oxford University Press. 
Olsen, P. I., Prenkert, F., Hoholm, T., \& Harrison, D. (2014). The dynamics of networked power in a concentrated business network. Journal of Business Research, 67(12), 2579-2589.

Reagans, R., \& McEvily, B. (2003). Network structure and knowledge transfer: The effects of cohesion and range. Administrative science quarterly, 48(2), 240-267.

Sambamurthy, V, \& Subramani, M. (2005). Special issue on information technology and knowledge management. Management Information Systems Quarterly, 29(2), 193195.

Tharenou, P., Donohue, R., \& Cooper, B. (2007). Management Research Methods. New York, NY: N Cambridge University Press.

Underwood, J. (2008). Varieties of Actor-Network Theory in Information Systems Research. In A. Brown (Ed.), Proceedings of 7th European Conference on Research Methodology for Business and Management Studies (pp. 285-291).

Villasalero, M. (2014). Intra-network knowledge roles and division performance in multibusiness firms. Journal of Knowledge Management, 18(6), 1165-1183.

Walter, J., Lechner, C., \& Kellermanns, F. W. (2007). Knowledge transfer between and within alliance partners: Private versus collective benefits of social capital. Journal of Business Research, 60(7), 698-710.

Woodside, A. G. (2013). Case Study Research: Theory, Methods, Practice. Emerald Group Publishing Limited. 
Table 1. Summary of the research participants and organizations

\begin{tabular}{|c|c|c|c|c|c|}
\hline Cases & $\begin{array}{l}\text { Nature of } \\
\text { company }\end{array}$ & $\begin{array}{l}\text { Company } \\
\text { abbreviati } \\
\text { on }\end{array}$ & $\begin{array}{l}\text { Business focus of } \\
\text { company }\end{array}$ & Interviewees & $\begin{array}{l}\text { Company } \\
\text { size } \\
\text { (number of } \\
\text { employees) }\end{array}$ \\
\hline 1 & $\begin{array}{l}\text { International } \\
\text { company }\end{array}$ & IPC & $\begin{array}{l}\text { culture of } \\
\text { partnership with a } \\
\text { strong } \\
\text { commercial focus }\end{array}$ & $\begin{array}{l}\text { 1- } \text { The head of project office } \\
\text { 2- } \text { Project manager } \\
\text { 3- } \text { Business analysis director } \\
\text { 4- } \text { IT Consultant } \\
\text { 5- } \quad \text { Total quality director }\end{array}$ & $180 \mathrm{~K}$ \\
\hline 2 & $\begin{array}{l}\text { International } \\
\text { company }\end{array}$ & ISS & $\begin{array}{l}\text { Industrial } \\
\text { Services } \\
\text { Company }\end{array}$ & $\begin{array}{l}\text { 6- Project manager (specializes in } \\
\text { health care projects) } \\
\text { 7- } \begin{array}{l}\text { Project manager (specialized in } \\
\text { national services projects) }\end{array} \\
\text { 8- } \text { Project manager (public } \mathrm{O} \text { ) }\end{array}$ & $150 \mathrm{~K}$ \\
\hline 3 & $\begin{array}{l}\text { Local } \\
\text { Company }\end{array}$ & LHZ & $\begin{array}{l}\text { Information } \\
\text { technology } \\
\text { services }\end{array}$ & $\begin{array}{l}\text { 9- Chief executives } \\
\text { 10- The head of project office } \\
\text { 11- The head of IT services } \\
\text { 12- Project Manager }\end{array}$ & 500 \\
\hline 4 & $\begin{array}{l}\text { Local } \\
\text { Company }\end{array}$ & LEM & $\begin{array}{l}\text { Information } \\
\text { Technology } \\
\text { services }\end{array}$ & $\begin{array}{l}\text { 13- Knowledge management officer } \\
\text { 14- Strategic management director } \\
\text { 15- The head of project office } \\
\text { 16- Project manager (specialized in } \\
\text { public organization) }\end{array}$ & 700 \\
\hline 5 & $\begin{array}{l}\text { Public } \\
\text { Organization } \\
\text { (Project } \\
\text { Centre) }\end{array}$ & PYR & $\begin{array}{l}\text { E-services } \\
\text { projects and } \\
\text { programs }\end{array}$ & $\begin{array}{l}\text { 17- Strategic management director } \\
\text { 18- The head of knowledge } \\
\text { management office } \\
\text { 19- The director of public } \\
\text { organization e-services } \\
\text { 20- The head of project office } \\
\text { 21- Project manager (specified in } \\
\text { internal projects) } \\
\text { 22- IT project consultant }\end{array}$ & 500 \\
\hline 6 & $\begin{array}{l}\text { Public } \\
\text { Organization }\end{array}$ & PIC & $\begin{array}{l}\text { Information } \\
\text { technology } \\
\text { services and } \\
\text { regulations }\end{array}$ & $\begin{array}{l}\text { 23- The director of IT services } \\
\text { 24- The head of project office } \\
\text { 25- The head of business strategy and } \\
\text { development office } \\
\text { 26- The director of communication } \\
\text { office } \\
\text { 27- Information officer }\end{array}$ & 300 \\
\hline 7 & $\begin{array}{l}\text { Public } \\
\text { organization }\end{array}$ & PNC & $\begin{array}{l}\text { Governmental E- } \\
\text { services }\end{array}$ & $\begin{array}{l}\text { 28- The assistant of general manager } \\
\text { 29- Organization's consultant } \\
\text { 30- Project manager (specified in IT } \\
\text { project between public and } \\
\text { private organization) } \\
\text { 31- Project manager (specified in } \\
\text { data center projects) } \\
\text { 32- Project manager (specified in } \\
\text { projects program management } \\
\text { and analysis) }\end{array}$ & 1200 \\
\hline 8 & Consultancy & $\begin{array}{l}\text { Consultant } \\
\text { s }\end{array}$ & $\begin{array}{l}\text { IT projects and IT } \\
\text { services and } \\
\text { regulations } \\
\text { consultancy }\end{array}$ & $\begin{array}{l}\text { 33- Vice president } \\
\text { 34- Chief executive }\end{array}$ & \\
\hline
\end{tabular}


Figure 1. Knowledge network model with organizations and knowledge channels

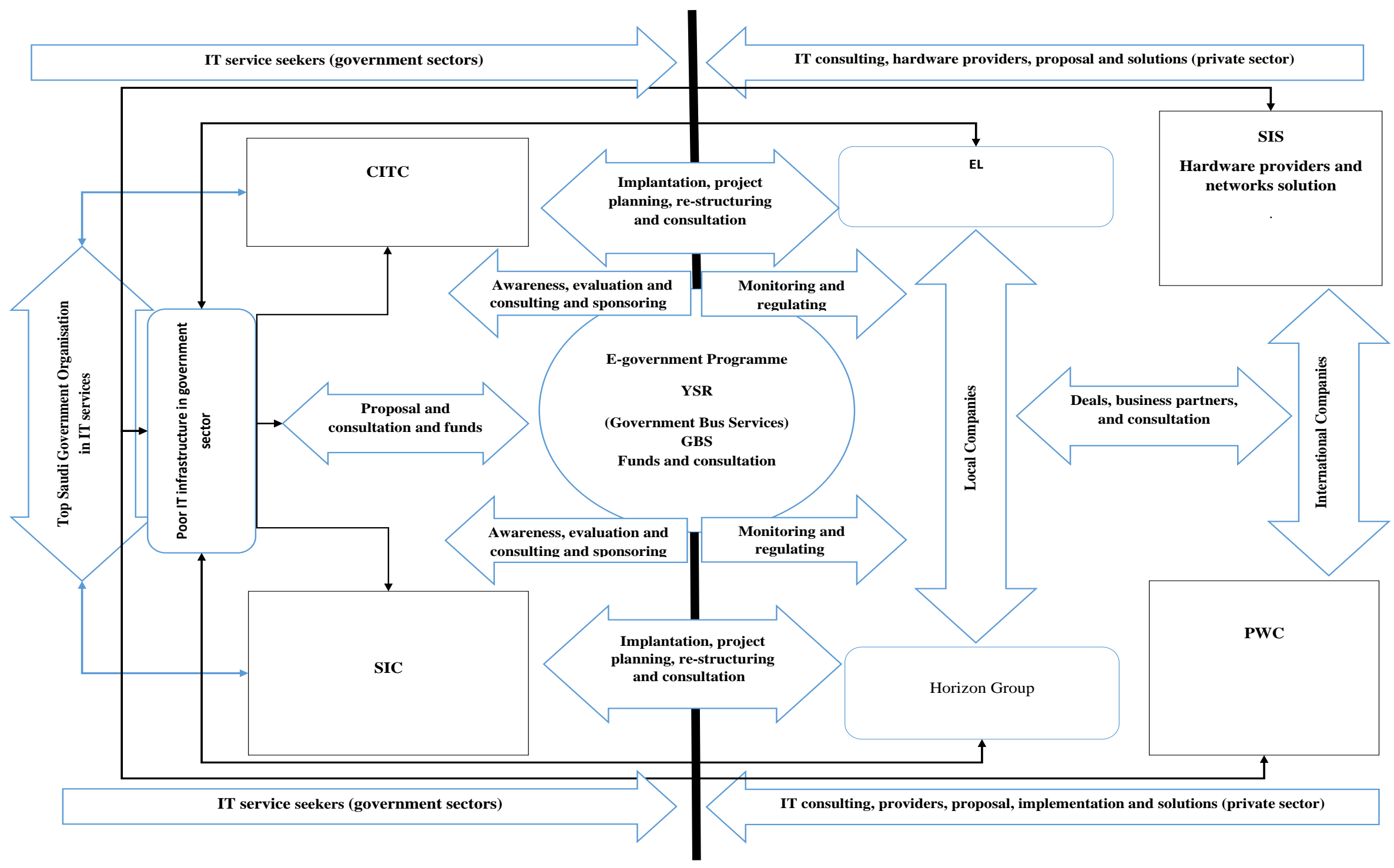

